\title{
A Child's View of Circulation in Prince William Sound, Alaska?
}

\author{
BY STEPHEN OKKONEN AND CLAUDE BÉLANGER
}

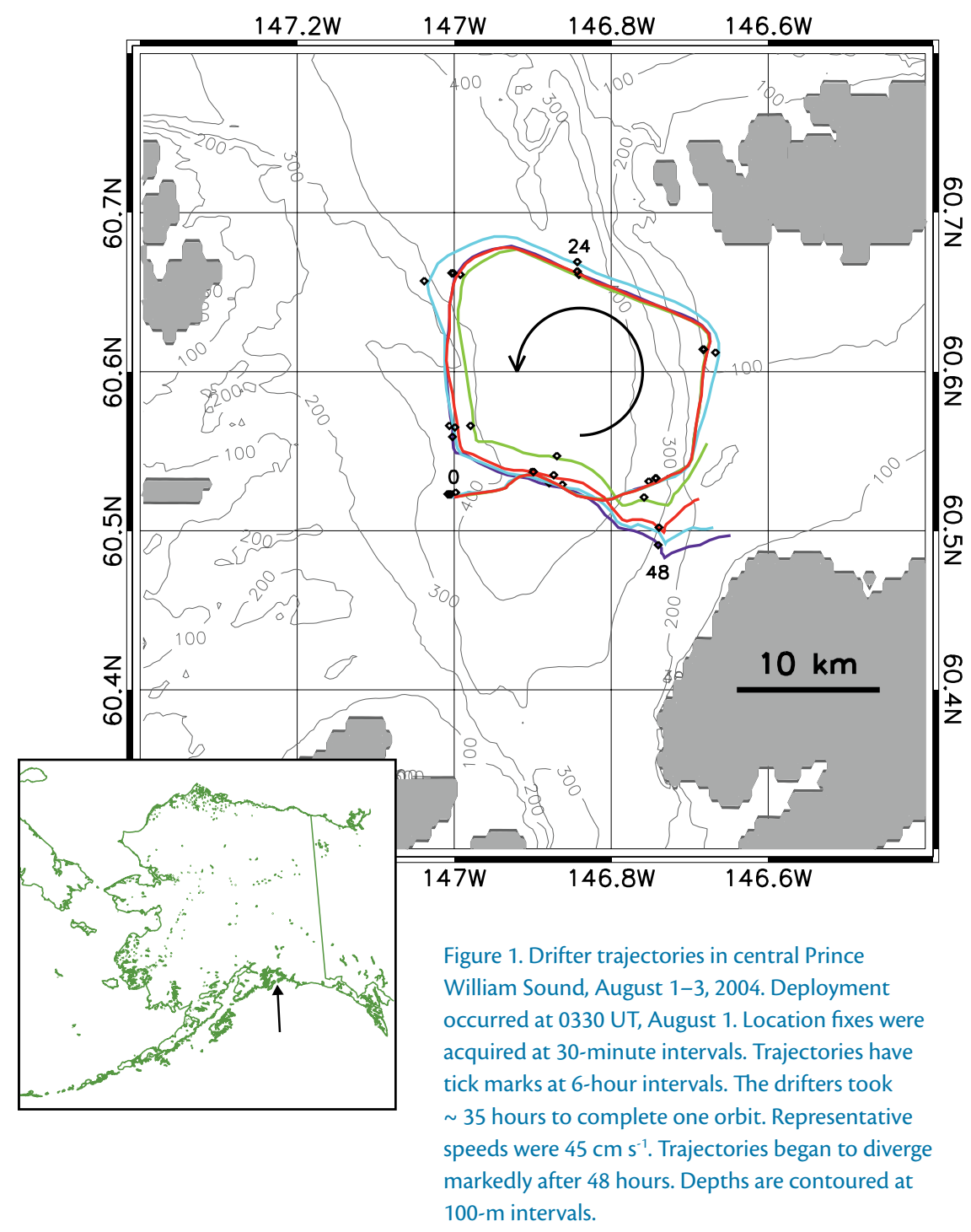

An oceanographic field exercise was conducted in central Prince William Sound, Alaska, in mid summer 2004 to evaluate the capability of the Prince William Sound Observing System to forecast the trajectories of surface drifting buoys (Cox, 2004). Interestingly, some drifters traced out quasi-polygonal trajectories (Figure 1) that brought to mind shapes created with a Spirograph.

As children or as adults with children, many of us have likely spent more than a few hours with paper, multicolored pens, and a Spirograph creating intriguing shapes that belong to the cycloid family of curves. Cycloids have the sobriquet "the Helen of geometers." This Homeric

Stephen Okkonen (okkonen@alaska. net) is Research Associate Professor, Institute of Marine Science, University of Alaska Fairbanks, Fairbanks, AK, USA. Claude Bélanger is Research Oceanographer, Prince William Sound Science Center, Cordova, AK, USA, and is currently at Institut National de la Recherche Scientifique-Eau, Terre et Environment, Québec, Canada. 
allusion derives from both the beauty of cycloids and the many disagreements among (especially $17^{\text {th }}$ century) mathematicians who devoted considerable study to this family of curves.

One branch of the cycloid family is a roulette traced by a point $\mathrm{P}$ on the edge of a circle of radius $\beta$ that rotates through angle $\Theta$ as the circle center moves through an angle of $\Phi$ while following a circular orbit of radius $\alpha$ (Figure 2).

The roulette, defined by the parametric equations

$\mathrm{x}=\alpha \cos \Phi+\beta \cos \Theta$

$y=\alpha \sin \Phi+\beta \sin \Theta$,

is called an epitrochoid if point $P$

rotates in the same direction as its orbital direction around the inner circle (i.e., $\Theta / \Phi>0$ ) and a hypotrochoid if point $\mathrm{P}$ rotates in the opposite direction as its orbital direction around the inner circle (i.e., $\Theta / \Phi<0$ ). Furthermore, for $|\Theta|>|\Phi|$, the epitrochoid will have $|\Theta / \Phi|-1=\mathrm{N}$ branches whereas the hypotrochoid will have $|\Theta / \Phi|+1=\mathrm{N}$ branches (Figure 3, top and middle plots). If $\mathrm{N}$ is not an integer, the branches of the roulette cross one another (Figure 3, bottom plot). The concavity (convexity) of the hypotrochoid (epitrochoid) branches depends, in part, on

\section{A CURIOSITY}

Prince William Sound (PWS) is a prominent embayment opening to the northern Gulf of Alaska. Wind and freshwater (buoyancy) forcing have large annual signals in the northern Gulf of Alaska (e.g., Wilson and Overland, 1986; Royer, 1982) and, along with tides, are significant drivers of circulation within PWS (with wind forcing being more

\section{Interestingly, some drifters traced out quasi-polygonal trajectories that brought to mind shapes created with a Spirograph.}

the ratio $\alpha / \beta$; the concavity or convexity becomes more pronounced as the ratio $\alpha / \beta$ becomes smaller (compare top and middle plots, Figure 3 ). important during the winter months and freshwater forcing being more important during the summer months). Large freshwater inputs to PWS along

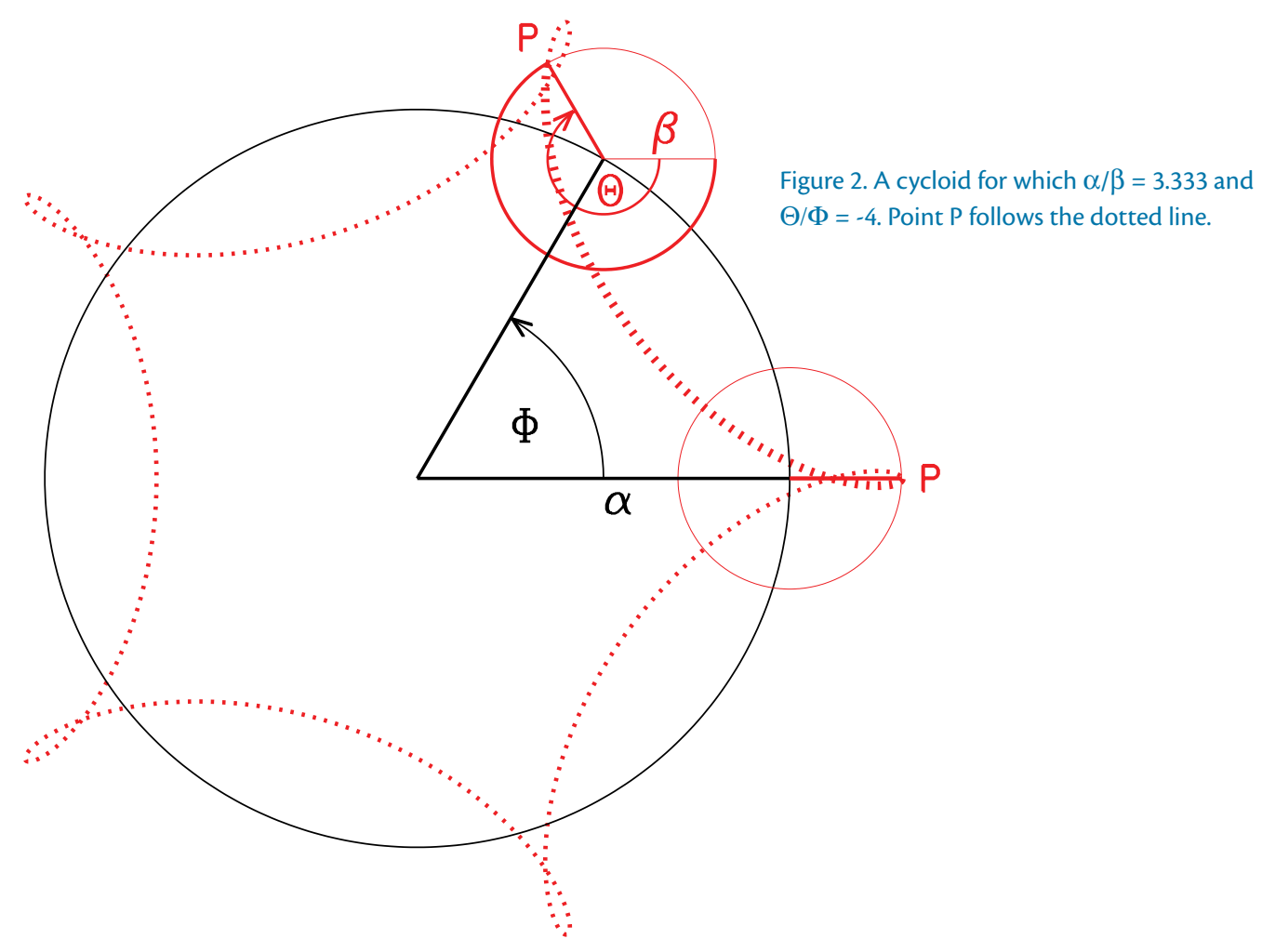



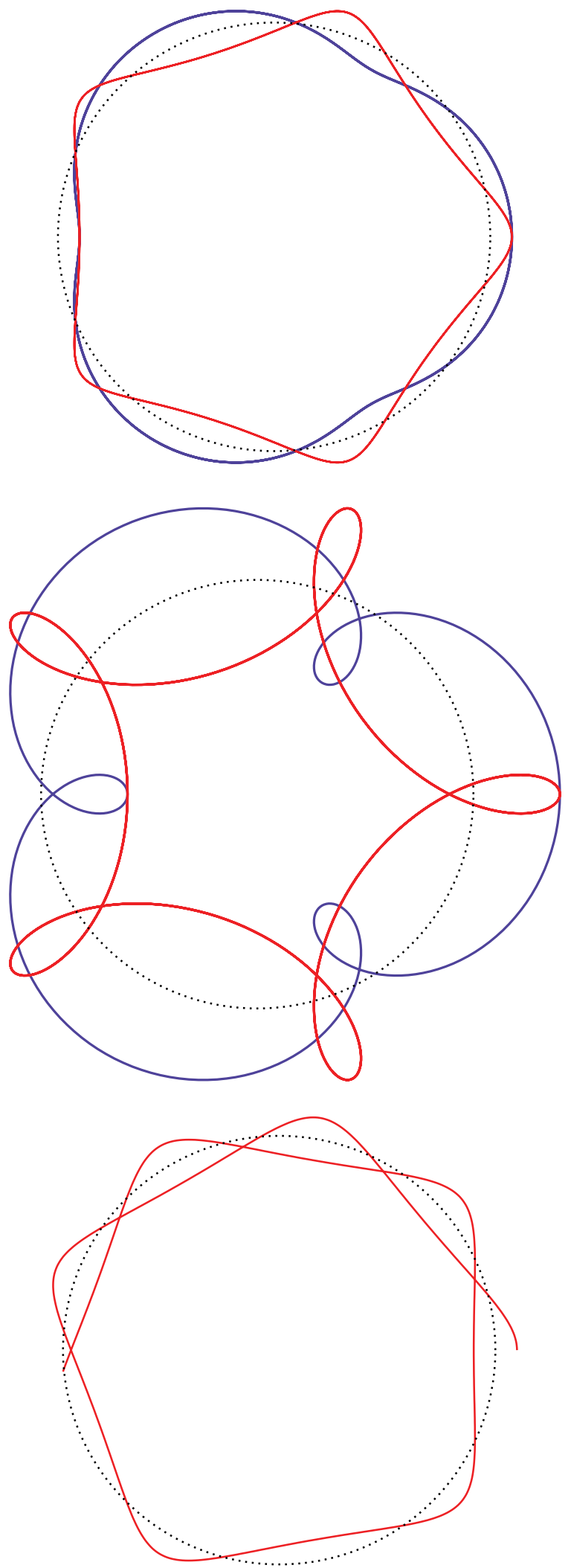

Figure 3. Examples of hypotrochoids (red) and epitrochoids (blue). (Top) $\alpha / \beta=10,|\Theta / \Phi|=4$. (Middle) $\alpha / \beta=2.5,|\Theta / \Phi|=4$.

(Bottom) $\alpha / \beta=10, \Theta / \Phi=-3.5$. The dotted circles have radii $=\alpha$. its perimeter promote counterclockwise, gyre-like circulation within the central sound during mid summer (Vaughn et al., 2001).

Three deployments of undrogued (Argosphere) surface drifters occurred during the field exercise.. The initial deployment (July 28,2004$)$ resulted in the drifters leaving central PWS in little more than a day, whereas the second (August 1, 2004) and third (August 4 , 2004) drifter deployments were of somewhat longer durations. Although gyre-like drifter trajectories were not unexpected, the quasi-polygonal drifter trajectories (cf. Figure 1) from the second deployment, in particular, caught our attention.

Fortuitously, winds were weak and, arguably, of little influence during the first 36 hours of this deployment (average wind speed was $1.9 \mathrm{~m} \mathrm{~s}^{-1}$ ), but stronger winds over the next 12 hours (average winds were from the northwest at $6.1 \mathrm{~m} \mathrm{~s}^{-1}$ ) likely contributed to the observed divergence in the drifter trajectories depicted in Figure 1.

In the absence of wind, the principal forces acting on these drifters are attributable to freshwater (gradients) and tides. Because the M2 tide is the dominant tidal constituent in PWS, we might reasonably represent the time series of drifter positions $\mathrm{x}(\mathrm{t}), \mathrm{y}(\mathrm{t})$ associated with the closed part of individual trajectories as the sum of a freshwater-driven gyral harmonic and a semidiurnal tidal harmonic, in other words, as a cycloid or Spirograph curve. The efficacy of this representation was tested by using a least squares procedure to fit the time series of observed drifter positions to the generalized parametric equations 


$$
\begin{aligned}
\mathrm{x}(\mathrm{t})= & \alpha_{\mathrm{x}} \cos \left(2 \pi \cdot \mathrm{t} / \tau_{\mathrm{Gx}}+\phi_{\mathrm{x}}\right)+ \\
& \beta_{\mathrm{x}} \cos \left(-2 \pi \cdot \mathrm{t} / \tau_{\mathrm{M} 2}+\theta_{\mathrm{x}}\right)+\mathrm{x}_{\mathrm{C}} \\
\mathrm{y}(\mathrm{t})= & \alpha_{\mathrm{y}} \sin \left(2 \pi \cdot \mathrm{t} / \tau_{\mathrm{Gy}}+\phi_{\mathrm{y}}\right)+ \\
& \beta_{\mathrm{y}} \sin \left(-2 \pi \cdot \mathrm{t} / \tau_{\mathrm{M} 2}+\theta_{\mathrm{y}}\right)+\mathrm{y}_{\mathrm{C}}
\end{aligned}
$$

in which $\alpha_{x, y}, \phi_{x, y}$, and $\tau_{G x, y}$ are the amplitudes, phase offsets, and periods (hours) for the $\mathrm{x}$ and $\mathrm{y}$ components of the freshwater-driven gyre circulation and $\Phi=2 \pi \cdot \mathrm{t} / \tau_{\mathrm{G}}$ (gyre circulation is counterclockwise). Similarly, $\beta_{x, y}, \theta_{x, y}$ and $\tau_{\mathrm{M} 2}$ are the amplitudes, phase offsets, and period for the $\mathrm{x}$ and $\mathrm{y}$ components of the semidiurnal (M2) tidal circulation and $\Theta=-2 \pi \cdot \mathrm{t} / \tau_{\mathrm{M} 2}(\mathrm{M} 2$ tidal currents rotate clockwise in central PWS). The center of the gyre-tide roulette is $x_{C}, y_{C}$.

Results from the least squares procedure indicate that the modeled tidal current speeds are reasonable and show that modeled trajectories closely resemble the actual trajectories, one example of which is shown in Figure 4. The analytical exercise and attendant results described above illustrate the importance of freshwater (as represented by the gyre circulation component) and tides as drivers of circulation in PWS and provide an aesthetically appealing demonstration that the underlying dynamics controlling the observed buoy trajectories are relatively simple.

\section{ACKNOWLEDGEMENTS}

We are grateful to Carl Schoch, Jack Barth, and an anonymous reviewer whose helpful suggestions improved the clarity of this manuscript. This project was supported by the Oil Spill Recovery
Institute and Prince William Sound Science Center, Cordova, Alaska, and by the National Oceanic and Atmospheric Administration. 可

\section{REFERENCES}

Cox, W. 2004. The Prince William Sound 2004 Lagrangian Field Experiment. Prince William Sound Science Center and Oil Spill Recovery Institute Report. 108 pp.

Royer, T.C. 1982. Coastal freshwater discharge in the northeast Pacific. Journal of Geophysical Research 87:2,017-2,021

Vaughn, S.L., C.N.K. Mooers, and S.M. Gay III. 2001. Physical variability in Prince William Sound during the SEA study (1994-98). Fisheries Oceanography 10(Suppl. 1):58-80.

Wilson, J.G., and J.E. Overland. 1986. Meteorology. Pp. 31-54 in The Gulf of Alaska. Physical Environment and Biological Resources, D.W. Hood and S.T. Zimmerman, eds, Alaska Office, Ocean Assessments Division, National Oceanic and Atmospheric Administration, US Dept. of Commerce. OCS study, MMS 86-0095.

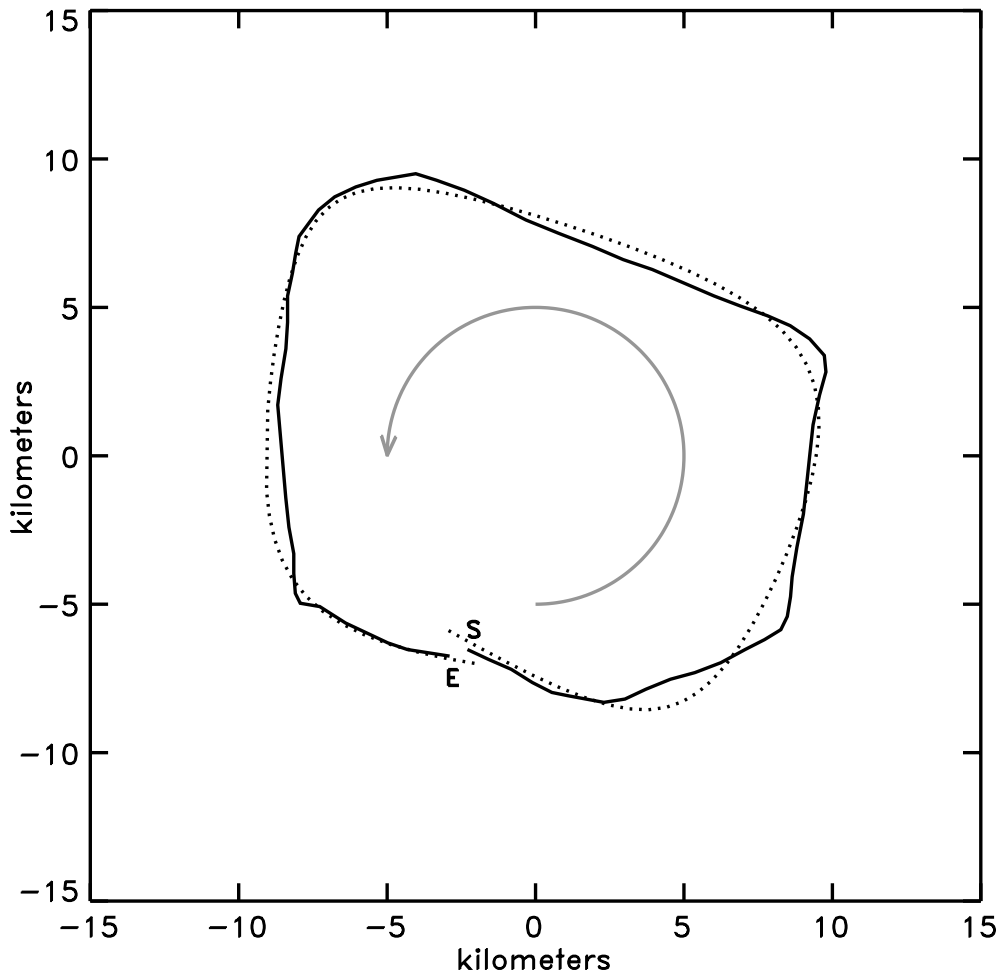

Figure 4. Representative drifter trajectory (solid) and modeled trajectory (dotted). The start $(S)$ and end $(E)$ points for the portion of the drifter trajectory used in the least squares procedure are shown. Least squares coefficients for the depicted modeled trajectory are:

- $\alpha_{x,} \alpha_{y}=9.65 \mathrm{~km}, 8.53 \mathrm{~km}$

- $\tau_{\mathrm{Gx},} \tau_{\mathrm{Gy}}=33.84 \mathrm{~h}, 33.37 \mathrm{~h}$

- $\phi_{x^{\prime}} \phi_{y}=-1.93,-2.19$

- $\beta_{x} \beta_{y}=0.87 \mathrm{~km}, 0.67 \mathrm{~km}$

- $\theta_{x^{\prime}} \theta_{y}=0.82,0.94$

The mean value for $\Theta / \Phi$ is -2.71 and the mean value for $\alpha / \beta$ is 11.91 . Representative speeds associated with the freshwater-driven gyre circulation and the semidiurnal tide are $\sim 47 \mathrm{~cm} \mathrm{~s}^{-1}$ and $\sim 11 \mathrm{~cm} \mathrm{~s}^{-1}$, respectively. Standard errors for modeled trajectories were less than $0.6 \mathrm{~km}$. 